\title{
Thermal Protection System Mass Estimating Relationships for Blunt-Body, Earth Entry Spacecraft
}

\author{
Steven A. Sepka ${ }^{1}$ \\ ERC Incorporated, Moffett Field, CA, 94035 \\ Jamshid A. Samareh ${ }^{2}$ \\ NASA Langley Research Center Hampton, VA 23681
}

\begin{abstract}
System analysis and design of any entry system must balance the level fidelity for each discipline against the project timeline. One way to inject high fidelity analysis earlier in the design effort is to develop surrogate models for the high-fidelity disciplines. Surrogate models for the Thermal Protection System (TPS) are formulated as Mass Estimating Relationships (MERs). The TPS MERs are presented that predict the amount of TPS necessary for safe Earth entry for blunt-body spacecraft using simple correlations that closely match estimates from NASA's high-fidelity ablation modeling tool, the Fully Implicit Ablation and Thermal Analysis Program (FIAT). These MERs provide a first order estimate for rapid feasibility studies. There are 840 different trajectories considered in this study, and each TPS MER has a peak heating limit. MERs for the vehicle forebody include the ablators Phenolic Impregnated Carbon Ablator (PICA) and Carbon Phenolic atop Advanced Carbon-Carbon. For the aftbody, the materials are Silicone Impregnated Reusable Ceramic Ablator (SIRCA), Acusil II, SLA-561V, and LI-900. The MERs are accurate to within 14\% (at one standard deviation) of FIAT prediction, and the most any MER under predicts FIAT TPS thickness is $\mathbf{1 8 . 7 \%}$. This work focuses on the development of these MERs, the resulting equations, model limitations, and model accuracy.
\end{abstract}

\section{Nomenclature}

$\begin{array}{ll}\mathrm{CW} & =\text { cold wall } \\ \mathrm{HL} & =\text { total heat load, } \mathrm{J} / \mathrm{cm}^{2} \\ \mathrm{MER} & =\text { mass estimating relationship } \\ \mathrm{P} & =\text { surface pressure, Pa } \\ \mathrm{SD} & =\text { standard deviation } \\ \mathrm{TH} & =\text { TPS thickness, } \mathrm{cm} \\ \mathrm{TPS} & =\text { thermal protection system } \\ \mathrm{V} & =\text { entry velocity, } \mathrm{km} / \mathrm{s} \\ \mathrm{V}_{\infty} & =\text { free stream velocity, } \mathrm{km} / \mathrm{s} \\ \rho_{\infty} & =\text { free stream density, } \mathrm{kg} / \mathrm{m}^{3}\end{array}$

\section{Introduction}

multidisciplinary, integrated tool called the "Multi Mission System Analysis for Planetary Entry Descent and Llanding," also known as M-SAPE ${ }^{1}$, is being developed as part of the Entry Vehicle Technology project under NASA's In-Space Propulsion Technology program. The primary purpose of M-SAPE is to perform system analysis and design for an Earth entry vehicle suitable for sample return missions. It includes geometry, mass sizing, impact analysis, structural analysis, flight mechanics, TPS, and a web portal for user access. It also provides a platform by which technologies and design elements can be evaluated rapidly prior to any costly investment commitment. An important feature of for M-SAPE is the ability to perform system analysis and trade studies in minutes and hours (not weeks or months). Part of M-SAPE's application requires the development of parametric mass estimating

\footnotetext{
${ }^{1}$ Senior Research Scientist, NASA-Ames Research Center, Thermal Protection Materials Branch (Code TSM) MS-234-1, Moffett Field, CA, 94035.

${ }^{2}$ Senior Aerospace Research Engineer, Vehicle Analysis Branch. 
relationships (MERs) to determine a vehicle's required Thermal Protection System (TPS). For this analysis, the heat shield is made of a uniform thickness TPS, and the resulting MERs determine the pre-flight mass of the TPS.

The analysis and design of a vehicle's safe Entry, Descent, and Landing (EDL) is very multidisciplinary in nature, requiring the application of Guidance, Navigation, and Control (GNC), aerodynamics, aerothermodynamics, and material response. A schematic diagram of the process is given in Fig. 1. For a typical re-entry problem, designers would first choose a payload, vehicle geometry, and subsequent vehicle mass. A trajectory is then determined by the use of GNC, with the trajectory uniquely identified by its entry velocity, entry flight path angle, and ballistic coefficient. The vehicle's aerothermal environment is then found by the use of computational aerothermodynamics. An aerothermal analysis will include convective and radiative heating, surface pressure, and recovery enthalpy. Once the entry environment is known, the TPS material response is modeled to determine the material thickness necessary to keep the bond line temperature below a specified value. It is also important to know the amount of surface recession, if any.

The traditional approach for this coupled problem would be to use a high fidelity computational fluid dynamics code such as the Data Parallel Line Relaxation ${ }^{2}$ (DPLR) code or the Langley Aeroheating Upwind Relaxation Algorithm $^{3}$ (LAURA) for the aerothermal component. For TPS response one could use the Fully Implicit Ablation and Thermal Response ${ }^{4}$ (FIAT) code, the Charring Material Thermal Response and Ablation Program ${ }^{5}$ (CMA), the Charring Ablating Thermal Protection Implicit System Solver ${ }^{6}$ (CHAR), or the Standard Ablation Program ${ }^{7}$ (STAB). However, this coupled approach usually has a very slow turnaround time and is highly dependent upon analyst availability.

The MERs developed in this work are to be used as alternates to high fidelity TPS material response codes such as FIAT or CHAR. The goal of the current work is to use these MERs in M-SAPE to screen a proposed trajectory to see if the vehicle's resulting TPS mass is too much or if a trajectories' heat rate exceeds a TPS limit.

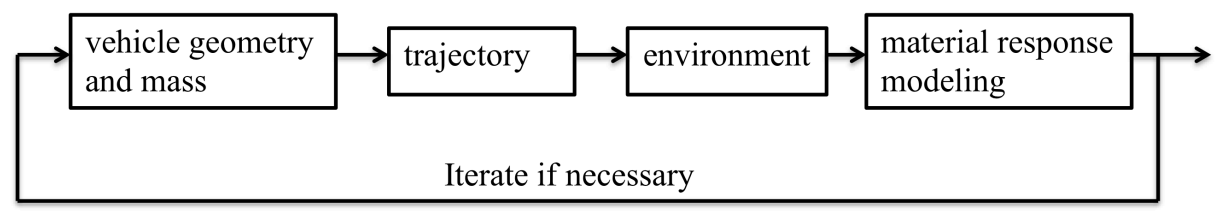

Figure 1. Flow chart of the EDL design process

For the vehicle forebody stagnation point, M-SAPE uses the Sutton - Graves ${ }^{8}$ correlation for convective heating and the Tauber - Sutton ${ }^{9}$ correlation for radiative heating. To date, however, no correlations based on high-fidelity FIAT modeling are known. As a result, the current work is to develop FIAT-based MERs that match FIAT prediction as closely as possible. Six MERs are developed. For the vehicle forebody the ablative materials are Phenolic Impregnated Carbon Ablator ${ }^{10}$ (PICA) and Carbon Phenolic ${ }^{11}$ atop Advanced Carbon-Carbon. For the vehicle aftbody the materials are Silicone Impregnated Reusable Ceramic Ablator ${ }^{12}$ (SIRCA), Acusil ${ }^{13}$ II, SLA$561 \mathrm{~V}$, and LI-900. As will be shown, the MERs are accurate to FIAT prediction within $14 \%$ at one standard deviation. For these MERs, no margins have been added to the TPS thickness.

Using these MERs, M-SAPE can now perform rapid trade studies involving entry velocity, ballistic coefficient, vehicle geometry, entry flight path angle, etc. for required TPS thickness and mass. Using these MERs have reduced design turnaround times for a possible Earth entry configuration from weeks to hours.

\section{MER Development}

\section{A. Concern Regarding the Application of MERs}

The MERs are statistical correlations developed to predict FIAT output. Each MER has with it a listed accuracy to the FIAT code's prediction, which is the standard deviation of the MER/FIAT thickness ratio over all sample trajectories.

The MER for each material has a maximum allowable instantaneous heat flux (combined convective and radiative). M-SAPE has correctly implemented this restriction into its code. If a trajectory's peak heating (found from the Sutton-Graves and Tauber-Sutton correlations) exceeded a TPS material's allowed value (see Table 4), then the trajectory was discarded and not included in the analysis.

It is emphasized that the MER thickness is not the manufacturing limit, and that substantial margin may be added. For example, Stardust flew with a PICA thickness ${ }^{14}$ of $5.816 \mathrm{~cm}(2.29$ inch), which is much greater than its unmargined thickness. 
Finally, as for any statistical analysis there exist some extreme trajectories for which the ratio of MER/FIAT TPS thickness prediction can well exceed the listed MER accuracy at one SD. For the present work, the largest MER under prediction of FIAT is $18.7 \%$. It is for this reason that full datasets are presented showing the curve fit and MER/FIAT "goodness-of-fit" data. M-SAPE uses these MERs as a rough approximation to determine TPS thickness for flight trajectories of interest, but a true high-fidelity analysis is always a requirement for a proposed mission.

\section{B. Flight Trajectory Parameters}

Found in Table 1 is information on the flight trajectory parameters used for this study. The range covers most of sample return applications from the Moon, Mars, and comets that are close to Earth orbit. The level accuracy reflects the needs for a conceptual level design.

Table 1. Flight trajectories considered for the MERs

\begin{tabular}{|l|c|c|}
\hline Flight Trajectory Parameter & Range of Values & Resolution \\
\hline Entry Velocity [km/s] & $10-16$ & 1 \\
\hline Entry Flight Path Angle [abs. deg.] & $5-25$ & 5 \\
\hline Ballistic Coefficient $\left[\mathrm{kg} / \mathrm{m}^{2}\right]$ & $41.95-128.74$ & $15.5(\mathrm{max})$ \\
\hline Total number of trajectories & 840 & - \\
\hline
\end{tabular}

Here, resolution is defined as a parameter's smallest step-size

\section{Vehicle Geometry Parameters}

The vehicle is a $60^{\circ}$ sphere-cone shape. Details of the vehicle geometry are given in Table 2 .

Table 2. Vehicle Geometry

\begin{tabular}{|l|c|c|}
\hline & $\min$ & $\max$ \\
\hline Nose Radius $[\mathrm{m}]$ & 0.352 & 0.352 \\
\hline Vehicle Diameter $[\mathrm{m}]$ & 0.75 & 2.25 \\
\hline Vehicle Mass $[\mathrm{kg}]$ & 16 & 159 \\
\hline Payload Mass $[\mathrm{kg}]$ & 5 & 30 \\
\hline
\end{tabular}

\section{FIAT modeling constraints}

FIAT analysis of each trajectory uses the following constraints:

- The maximum temperature at the bottom face of the top material (bond line) is $250^{\circ} \mathrm{C}$.

- The back face of the material stackup is adiabatic.

- The surrounding environment is at $21.3^{\circ} \mathrm{C}$ for radiation calculations from the spacecraft surface.

- 1D planar geometry

- No margins are added to the thickness

- FIAT v3.0

It should be noted that FIAT is a 1D code and is most applicable for heat shield regions that do not undergo rapid shape changes leading to large variations in aeroheating with spatial location. Examples of these regions include the stagnation point, along the flank, or any other acreage location. For regions that do change shape quickly, such as at the shoulder, a material response code like TITAN, ${ }^{15} 3 \mathrm{dFIAT}$, or CHAR is more appropriate because it includes $2 \mathrm{D}$ or 3D effects. In addition, PICA's heat conduction is orthotropic, which also necessitates the use of multidimensional codes along regions of the heat shield that change shape quickly. Shown in Table 3 are the ranges of sample trajectory heating rates, heat loads, and surface pressures used in the FIAT analysis of the 840 sample flight trajectories. The data shown in this table are prior to MER development.

Table 3. Range of surface heating, heat load, and surface pressure.

\begin{tabular}{|l|c|c|}
\hline & Forebody & Aftbody \\
\hline Maximum heat flux $\left[\mathrm{W} / \mathrm{cm}^{2}\right]$ & $151-3767$ & $2-58$ \\
\hline Heat Load $\left[\mathrm{J} / \mathrm{cm}^{2}\right]$ & $3855-34453$ & $59-531$ \\
\hline Maximum pressure, atm & $0.03-3.18$ & $0.003-1.64$ \\
\hline
\end{tabular}

\section{E. Methodology}




\section{MER Formulation}

The variables considered to create the MERs included peak heat flux, peak surface pressure, heat load, ballistic coefficient, entry velocity, and entry flight path angle. To determine which of these variables to use, sensitivity studies were conducted by plotting the value of each variable against required TPS thickness for all trajectories. Viewing these scatter plots and calculating correlation coefficients determined if any correlation or sensitivity existed. For this work, heat load and entry velocity were chosen for the MER correlations. We have selected a ratio of heat load over square of velocity as the correlation parameter that represents the ratio of entry thermal energy over entry kinetic energy. The resulting MER accuracy is sufficient to meet M-SAPE's needs.

\section{Forebody Calculations}

The form of the Sutton-Graves relation used by M-SAPE is a cold-wall (CW) convective heat flux. Consequently, the convective heat load used in the MERs is CW. For the radiative heat load, the Tauber-Sutton relation was used to estimate the radiative heating. Stagnation pressure was found using the momentum equation:

$$
P=\rho_{\infty} V_{\infty}^{2}
$$

When FIAT ran through all 840 trajectories, 123 of them were so mild as to produce no recession or ablation for PICA and Carbon Phenolic. For such mild environments, the proper heat shield material is an insulator rather than an ablator. As a result, these mild trajectories were not used in the forebody MERs, and the MER minimum thickness was chosen from the trajectories that cause any ablation. This minimum thickness is enough material to keep the bond line temperature below $250^{\circ} \mathrm{C}$ for all trajectories.

\section{Aftbody Calculations}

To estimate the aerothermal environment on the aftbody, convective heating was found by taking $5 \%$ of the forebody stagnation point heating. This value is consistent with a study showing Viking ${ }^{16}$ aftbody (base) heating to be about $5 \%$ of Sutton-Graves forebody heating. On the aftbody, radiative heating was ignored. Aftbody surface pressures are suggested to be $30 \%$ of forebody based on Earth re-entry flight test data ${ }^{17}$ using slender cones with blunted nose tips and a nearly flat base. For this work, a surface pressure of $50 \%$ of the forebody stagnation point value was used as a conservative estimate.

\section{F. Summary of Results}

The results are summarized in Table 4. A discussion of these results, how they were obtained, and their accuracy is given in Section III.

Table 4. Summary of results.

\begin{tabular}{|c|c|c|c|c|c|c|}
\hline & \multicolumn{2}{|c|}{ Forebody } & \multicolumn{4}{|c|}{ Aftbody } \\
\hline & PICA & CP/ACC & SIRCA & Acusil II & LI-900 & SLA-561V \\
\hline $\begin{array}{l}\text { Max allowable } \\
\text { heat flux, CW } \\
{\left[\mathrm{W} / \mathrm{cm}^{2}\right]}\end{array}$ & 1200 & 30000 & 100 & 100 & 75 & 100 \\
\hline Recession $[\mathrm{cm}]$ & $0.60-1.15$ & $0.0002-0.141$ & none & none & none & none \\
\hline $\begin{array}{l}\text { Accuracy to } \\
\text { FIAT [one SD] }\end{array}$ & $6.3 \%$ & $7.3 \%$ & $8.5 \%$ & $7.6 \%$ & $14.0 \%$ & $8.5 \%$ \\
\hline $\begin{array}{l}\text { Largest under } \\
\text { prediction }[\% \text { of } \\
\text { FIAT] }\end{array}$ & 11.7 & 16.6 & 15.6 & 15.1 & 18.7 & 15.7 \\
\hline $\begin{array}{l}\text { Minimum } \\
\text { thickness }[\mathrm{cm}]\end{array}$ & 3.27 & 2.27 & 0.518 & 0.614 & 0.686 & 0.454 \\
\hline Thickness $[\mathrm{cm}]$ & $1.8696\left(\frac{H L}{V^{2}}\right)^{0.1873}$ & $1.1959\left(\frac{H L}{V^{2}}\right)^{0.102}$ & $0.5281\left(\frac{H L}{V^{2}}\right)^{0.5416}$ & $0.623\left(\frac{H L}{V^{2}}\right)^{0.5697}$ & $\begin{array}{c}\mathrm{q}_{\mathrm{CW}}<=10 \mathrm{~W} / \mathrm{cm}^{2} \\
0.6961\left(\frac{H L}{V^{2}}\right)^{0.056} \\
\mathrm{q}_{\mathrm{CW}}>10 \mathrm{~W} / \mathrm{cm}^{2} \\
-0.0306\left(\frac{H L}{V^{2}}\right)^{2}+0.5896\left(\frac{H L}{V^{2}}\right)+0.6739\end{array}$ & $0.0064\left(\frac{H L}{V^{2}}\right)^{2}+0.0961\left(\frac{H L}{V^{2}}\right)+0.3322$ \\
\hline
\end{tabular}

\section{Forebody MER Development: PICA and Carbon Phenolic}

\section{1. $P I C A$}

Phenolic Impregnated Carbon Ablator (PICA) is a low-density, high performance ablator that uses a porous rigid carbon-fiber substrate impregnated with a dispersed phenolic polymer. It has a nominal density of $0.274 \mathrm{~g} / \mathrm{cm}^{3}(17.1$ $\left.\mathrm{lb} / \mathrm{ft}^{3}\right) .{ }^{18}$ PICA has successfully flown as the main forebody heat shield material on the Stardust Sample Return Capsule (SRC) ${ }^{19}$ and on the Mars Science Laboratory (MSL) capsule. ${ }^{20}$ 
The material stackup for this MER consists of only PICA, and the FIAT PICA material response model was version 3.3. The MER is given in Eq. 2, and it has a standard deviation of $6.3 \%$ to FIAT prediction. Specifics of the correlation model are given in Table 5. Figure 2 shows the MER fit of the data, and a scatter plot of Goodness of Fit (GoF) with FIAT-predicted TPS thickness is given in Fig. 3. GoF is defined as the ratio of MER to FIAT prediction.

$$
T H=1.8686\left(\frac{H L}{V^{2}}\right)^{0.1879}
$$

Table 5. PICA MER Details

\begin{tabular}{|l|c|}
\hline Variable & Values \\
\hline Maximum allowable heat flux, W/cm ${ }^{2}, \mathrm{CW}$ & 1200 \\
\hline Recession, cm & $0.134-1.153$ \\
\hline Accuracy to FIAT at one SD & $6.3 \%$ \\
\hline Largest under prediction of FIAT $(\%$ of FIAT) & 11.7 \\
\hline Number of trajectories with no recession & 123 \\
\hline Trajectories used for correlation & 419 \\
\hline Minimum thickness, cm & 3.27 \\
\hline
\end{tabular}

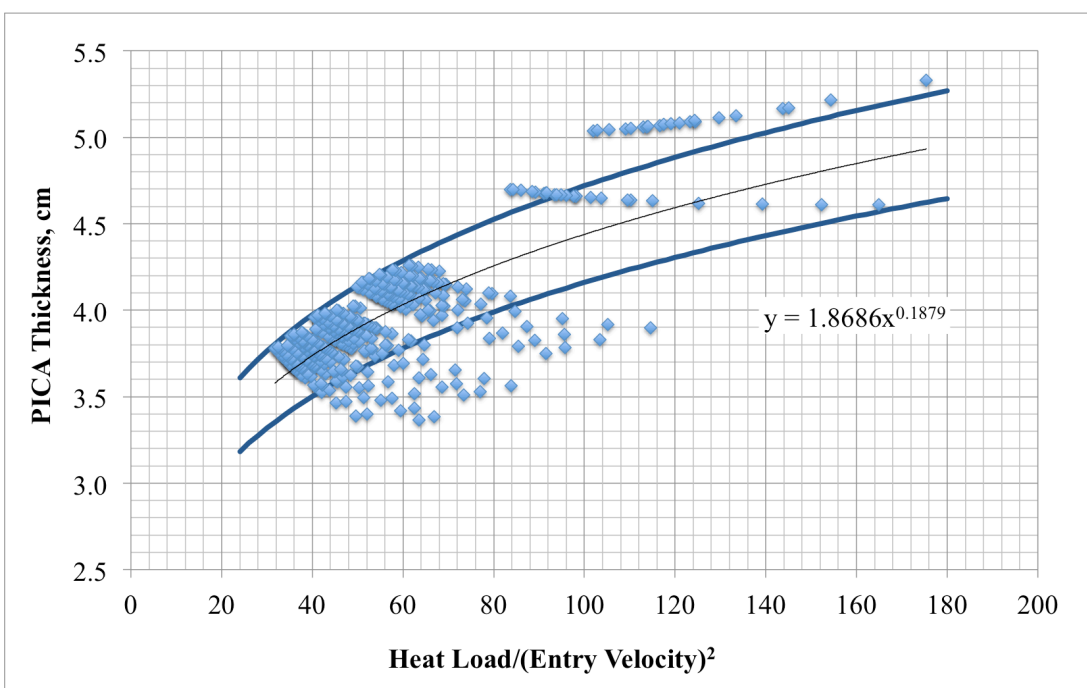

Figure 2. PICA MER banded by 1 standard deviation

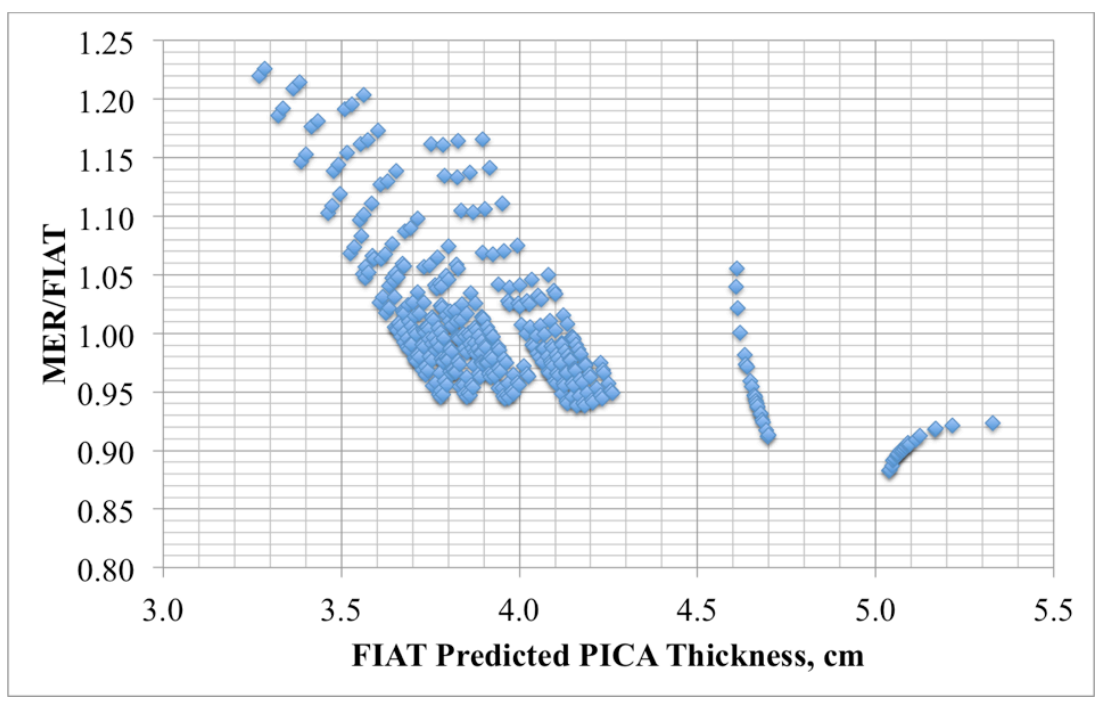

5

$45^{\text {th }}$ AIAA Thermophysics Conference, Dallas Texas

June 22-26, 2015 
Figure 3. PICA MER Goodness of Fit

\section{Carbon Phenolic Atop Advanced Carbon-Carbon 6}

Carbon Phenolic is a high-density ablator capable of withstanding extremely high heat flux environments. The maximum allowable heat flux for this material is an amazing $30 \mathrm{~kW} / \mathrm{cm}^{2}$, which it approximately experienced on the Galileo Jupiter Probe planetary entry. ${ }^{21}$ Carbon phenolic has also been used on the four Pioneer Venus probes. ${ }^{22}$ There are different methods to fabricate this material, and the one used for this work was specified as FM-5055. ${ }^{23}$ The virgin material density ${ }^{24}$ is $1.43 \mathrm{~g} / \mathrm{cm}^{3}\left(89.6 \mathrm{lb} / \mathrm{ft}^{3}\right)$.

For this MER, the material stackup is given in Table 6, with ACC6 as the carrier structure.

Table 6. Material stackup

\begin{tabular}{|l|c|}
\hline Material & Thickness, cm \\
\hline Carbon Phenolic & variable \\
\hline HT-424 (adhesive) & 0.0381 \\
\hline Advanced Carbon-Carbon (ACC) version 6 & 0.250 \\
\hline
\end{tabular}

This MER is given in Eq. 3, and it has a standard deviation of 7.3\% to FIAT prediction. Specifics of the MER are given in Table 7. A scatter plot showing the fit to the data is given in Fig. 4, and Fig. 5 shows a scatter plot of GoF with FIAT-predicted TPS thickness.

$$
T H=1.1959\left(\frac{H L}{V^{2}}\right)^{0.2102}
$$

Table 7. Carbon Phenolic atop ACC MER Details

\begin{tabular}{|l|c|}
\hline Variable & Values \\
\hline Maximum allowable CW heat flux, W/cm ${ }^{2}$ & 30000 \\
\hline Recession [cm] & $0.0002-0.1416$ \\
\hline Accuracy to FIAT at one SD & $7.3 \%$ \\
\hline Largest under prediction of FIAT (\% of FIAT) & 16.6 \\
\hline Number of FIAT non-convergent trajectories & 16 \\
\hline Trajectories with no recession & 123 \\
\hline Trajectories used for correlation & 701 \\
\hline Minimum thickness, cm & 2.266 \\
\hline
\end{tabular}

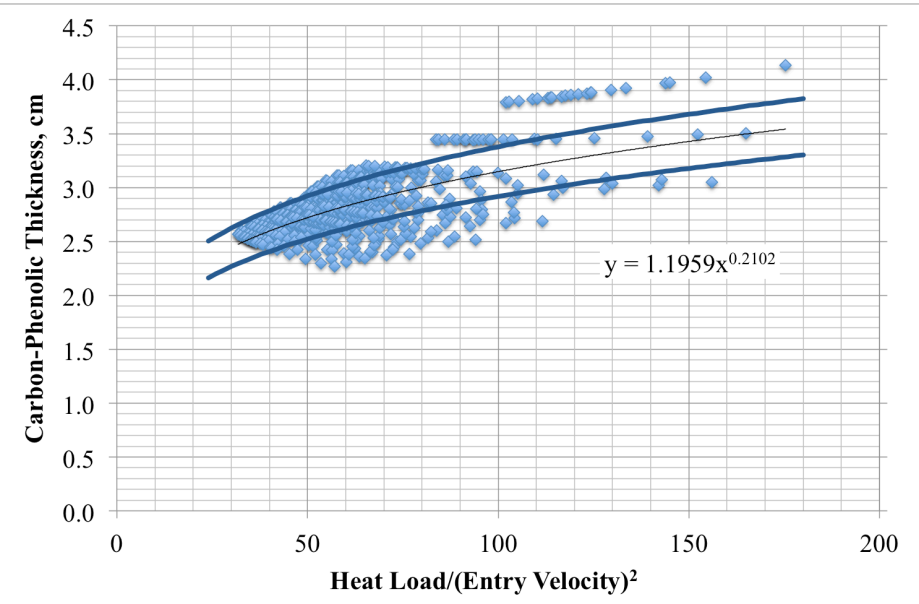

Figure 4. Carbon Phenolic over ACC6 MER banded by 1 standard deviation. 


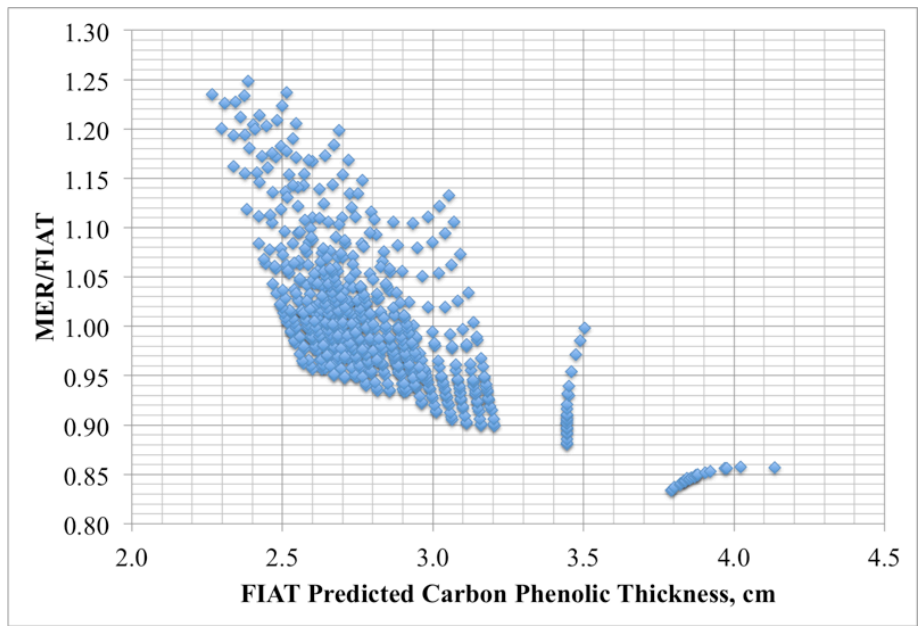

Figure 5. Carbon Phenolic over ACC6 MER GoF.

\section{Vehicle Backshell MERs}

1. SIRCA

Silicone Impregnated Reusable Ceramic Ablator (SIRCA) is an insulative, ablative TPS material that is easily machined to custom shapes. Machined SIRCA tiles are then applied directly to the spacecraft. The nomenclature of SIRCA-15F refers to SIRCA tile manufactured from $0.19 \mathrm{~g} / \mathrm{cm}^{3}\left(12 \mathrm{lb} / \mathrm{ft}^{3}\right)$ bulk density fibrous refractory ceramic insulation (FRCI-12), with a final SIRCA bulk density of $0.264 \pm 0.024 \mathrm{~g} / \mathrm{cm}^{3}\left(16.5 \pm 1.5 \mathrm{lb} / \mathrm{ft}^{3}\right) .{ }^{25}$ For this study, a virgin density of $0.259 \mathrm{~g} / \mathrm{cm}^{3}\left(16.2 \mathrm{lb} / \mathrm{ft}^{3}\right)$ was used for modeling material response. SIRCA has been used successfully as an aftbody TPS material for Mars Pathfinder ${ }^{26}$ and Mars Exploration Rovers. ${ }^{27}$ For these probes, the Backshell Interface Plate (BIP) was covered with SIRCA tiles.

The material stackup for this MER consists only of SIRCA, and the FIAT SIRCA model is version 1.00. The SIRCA MER is given in Eq. 4, and it has a standard deviation of $7.4 \%$ to FIAT prediction. Specifics of the MER are given in Table 8. Shown in Fig. 6 is the MER fit of the data, and a scatter plot of Goodness of Fit with FIATpredicted TPS thickness is given in Fig. 7.

$$
T H=0.5281\left(\frac{H L}{V^{2}}\right)^{0.5416}
$$

Table 8. SIRCA MER Details

\begin{tabular}{|l|c|}
\hline Variable & Values \\
\hline Maximum allowable CW heat flux, W/cm & 100 \\
\hline Recession, cm & none \\
\hline Accuracy to FIAT at one SD & $7.4 \%$ \\
\hline Largest under prediction of FIAT (\% of FIAT) & 16.6 \\
\hline Trajectories used for correlation & 835 \\
\hline Minimum thickness, cm & 0.614 \\
\hline
\end{tabular}




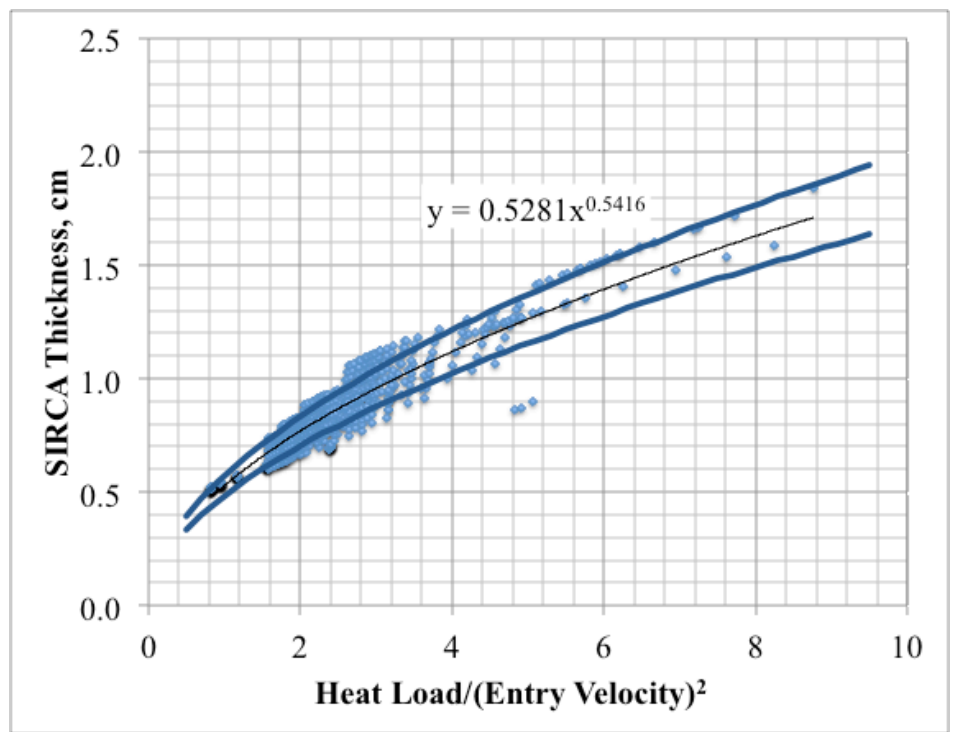

Figure 6. SIRCA MER banded by one standard deviation

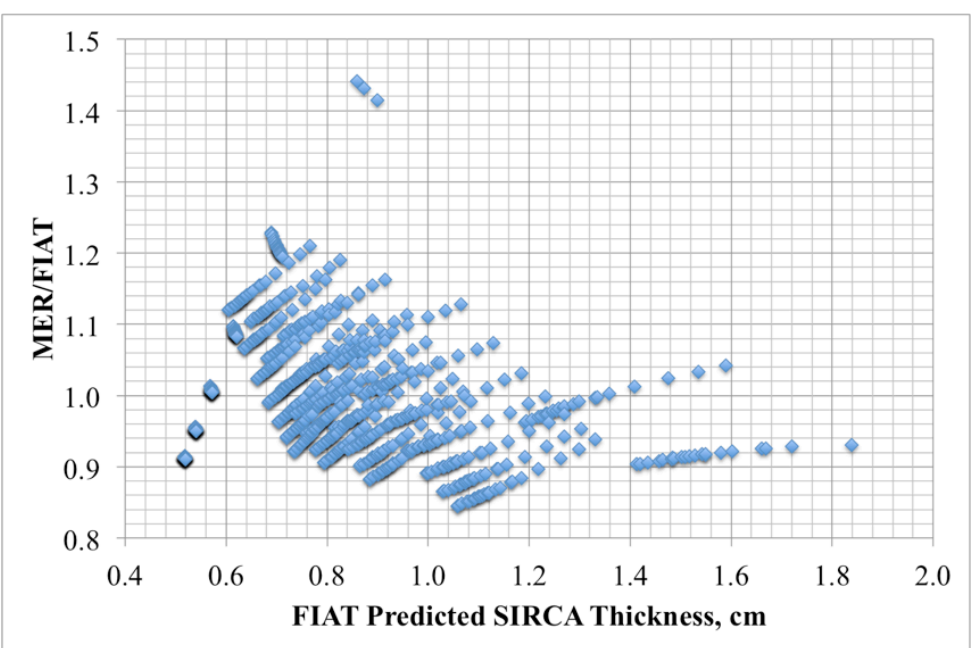

Figure 7. SIRCA MER Goodness of Fit

\section{Acusil II}

Acusil II is a silicone foam material that can be molded to cover complex surface geometries. ${ }^{28}$ This material was used on the Mars Science Laboratory ${ }^{29}$ aftbody to protect the parachute cone cover (PCC) and backshell interface plate (BIP). It has a nominal density of about $0.25 \mathrm{~g} / \mathrm{cm}^{3}\left(16 \mathrm{lb} / \mathrm{ft}^{3}\right)$.

The Acusil II MER is given in Eq. 5, and it has a standard deviation of $7.6 \%$ to FIAT prediction. Specifics of the MER are given in Table 9. Shown in Fig. 8 is the MER fit of the data, and a scatter plot of Goodness of Fit with FIAT-predicted TPS thickness is given in Fig. 9.

$$
T H=0.623\left(\frac{H L}{V^{2}}\right)^{0.5697}
$$


Table 9. Acusil II MER Details

\begin{tabular}{|l|c|}
\hline Variable & Values \\
\hline Maximum allowable CW heat flux, W/cm ${ }^{2}$ & 100 \\
\hline Recession, cm & none \\
\hline Accuracy to FIAT at one SD & $7.6 \%$ \\
\hline Largest under prediction of FIAT (\% of FIAT) & 15.1 \\
\hline Trajectories used for correlation & 835 \\
\hline Minimum thickness, cm & 0.614 \\
\hline
\end{tabular}

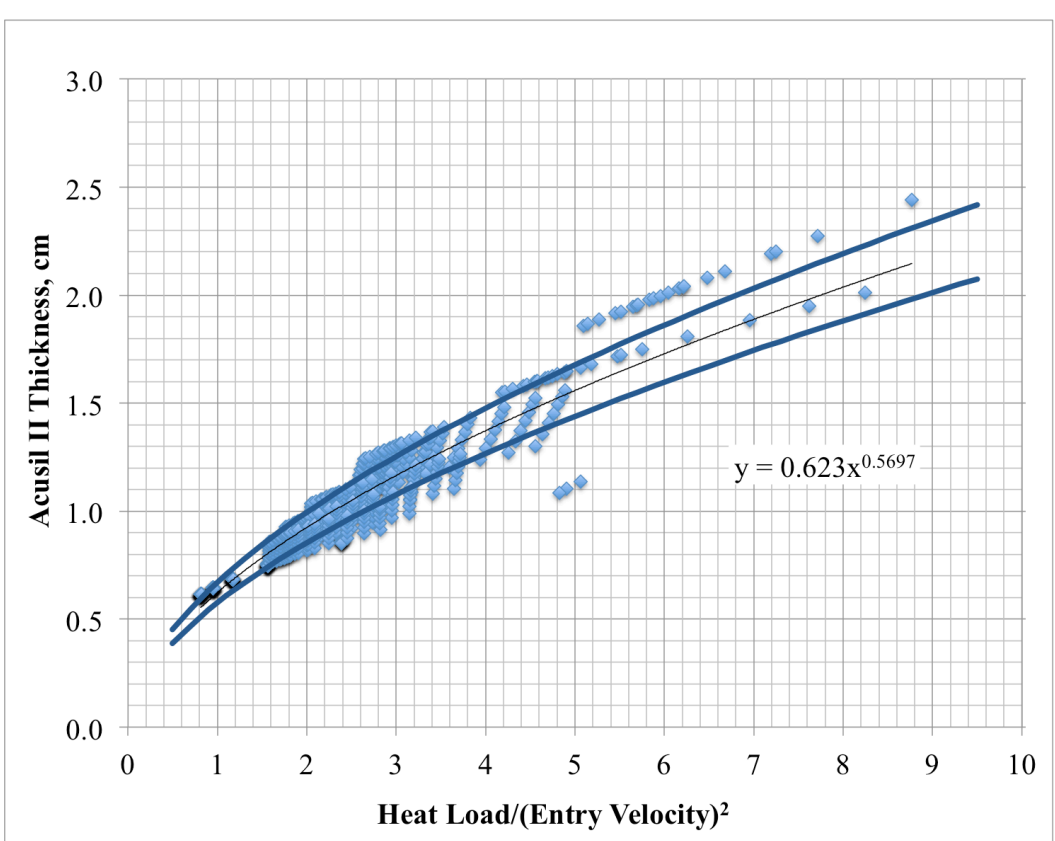

Figure 8. Acusil II MER

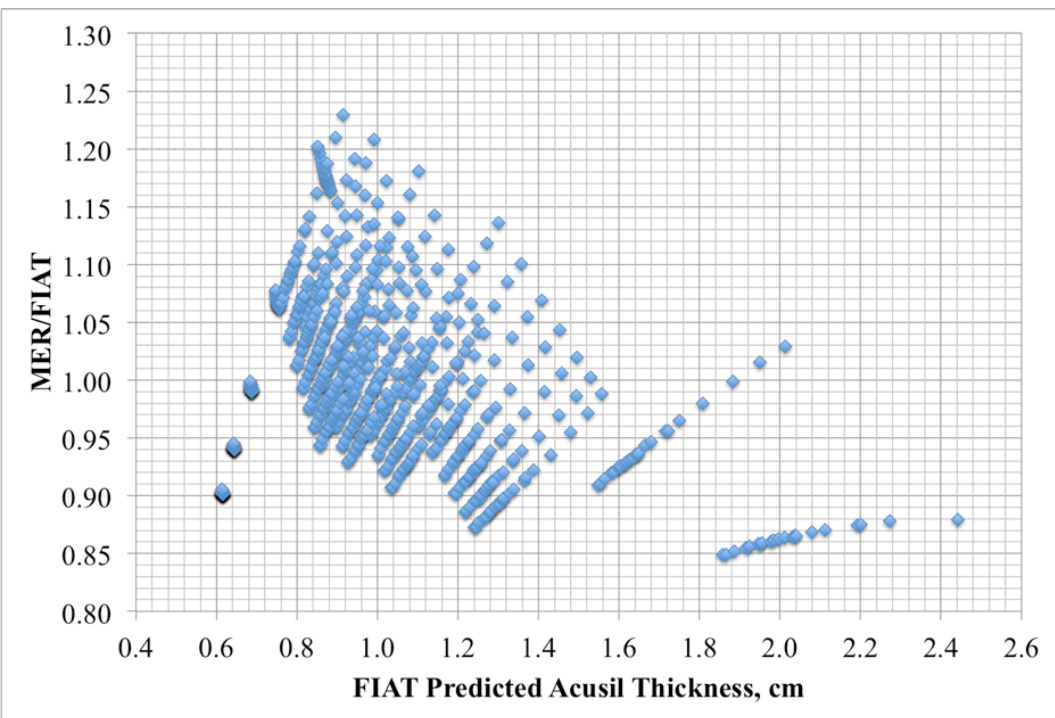

\section{Figure 9. Acusil II MER GoF}

3. SLA-561V

SLA-561V is a filled cork silicone packed in a phenolic fiberglass honeycomb. ${ }^{30}$ It contains a room temperature vulcanizing (RTV) silicone resin, granulated cork, silica and phenolic microballoons, and chopped Refrasil fibers. The nominal density of the virgin material is about $0.256 \mathrm{~g} / \mathrm{cm}^{3}\left(16 \mathrm{lb} / \mathrm{ft}^{3}\right)$. 
For this MER, SLA-561V is listed as an aftbody heat shield material because forebody peak heating is at least $151 \mathrm{~W} / \mathrm{cm}^{2}$ (cold-wall). However, this material has been used on the forebody TPS for all Mars probes with the exception of Mars Science Laboratory. ${ }^{31}$

The SLA-561V MER is given in Eq. 6, and it has a standard deviation of $8.5 \%$ to FIAT prediction. Specifics of the MER are given in Table 10. Shown in Fig. 10 is the MER fit of the data, and a scatter plot of Goodness of Fit with FIAT-predicted TPS thickness is given in Fig. 11.

$$
T H=0.0064\left(\frac{H L}{V^{2}}\right)^{2}+0.0961\left(\frac{H L}{V^{2}}\right)+0.3322
$$

Table 10 SLA-561V MER Details

\begin{tabular}{|l|c|}
\hline Variable & Values \\
\hline Maximum allowable CW heat flux, W/cm & 100 \\
\hline Recession, cm & none \\
\hline Accuracy to FIAT at one SD & $8.5 \%$ \\
\hline Largest under prediction of FIAT (\% of FIAT) & 15.7 \\
\hline Trajectories used for correlation & 835 \\
\hline Minimum thickness, cm & 0.454 \\
\hline
\end{tabular}

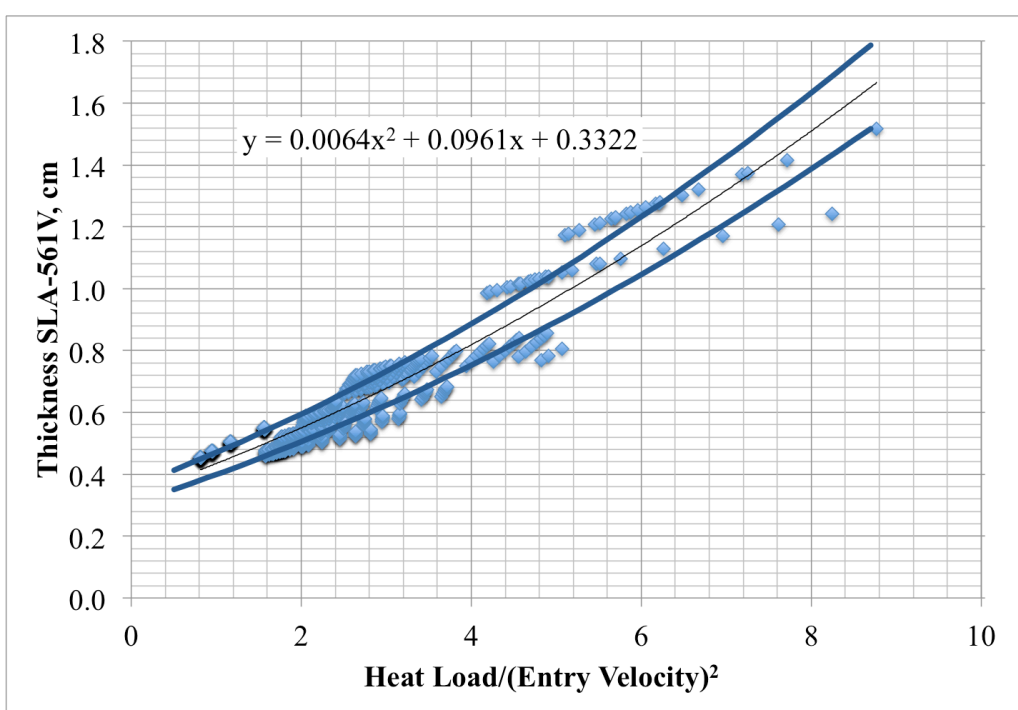

Figure 10. SLA-561V MER 


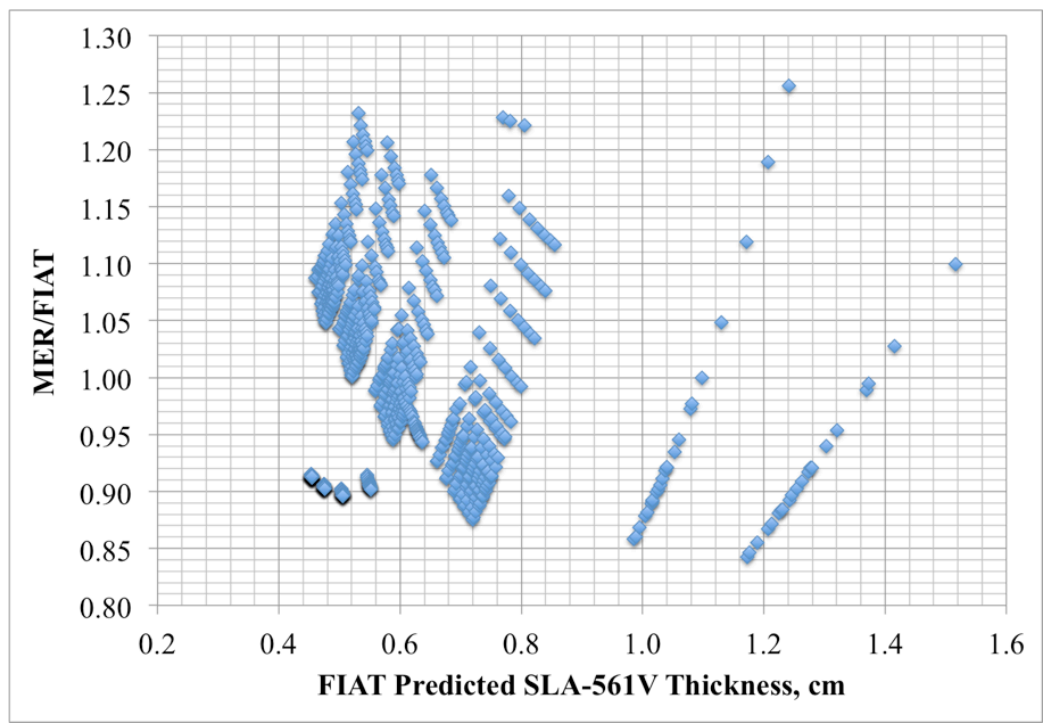

\section{Figure 11. SLA-561V MER Goodness of Fit}

\section{4. $L I-900$}

LI-900 tiles are made from $99.9 \%$ pure silica glass fibers ${ }^{32}$ and are $94 \%$ air by volume. The nominal density of LI-900 is $0.144 \mathrm{~g} / \mathrm{cm}^{3}\left(9 \mathrm{lb} / \mathrm{ft}^{3}\right)$. These tiles were used on the lower surface of the Space Shuttle Orbiter. ${ }^{33}$ For this MER, the LI-900 surface is uncoated. Having no surface coating results in a conservative sizing estimate due to an uncoated surface having a lower surface emittance ${ }^{34}$ and consequently lower radiation from the vehicle surface during entry. There was no radiation to the vehicle aftbody, so absorptivity did not have any effect on surface heating.

Although the ratio of heat load and the square of entry velocity is kept as an independent variable, the LI-900 MER is divided by peak heat flux into two separate equations. This was done to increase MER accuracy. These relations are given in Eq. 7. The MER has a standard deviation of $14.0 \%$ to FIAT prediction. Specifics of the MER are given in Table 7. Shown in Fig. 12 is the MER fit of the data, and a scatter plot of Goodness of Fit with FIATpredicted TPS thickness is given in Fig. 13.

$$
\left.\begin{array}{cc}
T H=0.6961\left(\frac{H L}{V^{2}}\right)^{0.656} & q_{c w} \leq 10 \frac{W}{c m^{2}} \\
T H=-0.0306\left(\frac{H L}{V^{2}}\right)^{2}+0.5896\left(\frac{H L}{V^{2}}\right)+0.6739 & q_{c w}>10 \frac{W}{c^{2}}
\end{array}\right\}
$$

Table 1 LI-900 MER Details

\begin{tabular}{|l|c|}
\hline Variable & Values \\
\hline Maximum allowable CW heat flux, W/cm & 75 \\
\hline Recession, cm & none \\
\hline Accuracy to FIAT at one SD & $14 \%$ \\
\hline Largest under prediction of FIAT (\% of FIAT) & 18.7 \\
\hline Trajectories used for correlation & 798 \\
\hline Minimum thickness, cm & 0.686 \\
\hline
\end{tabular}




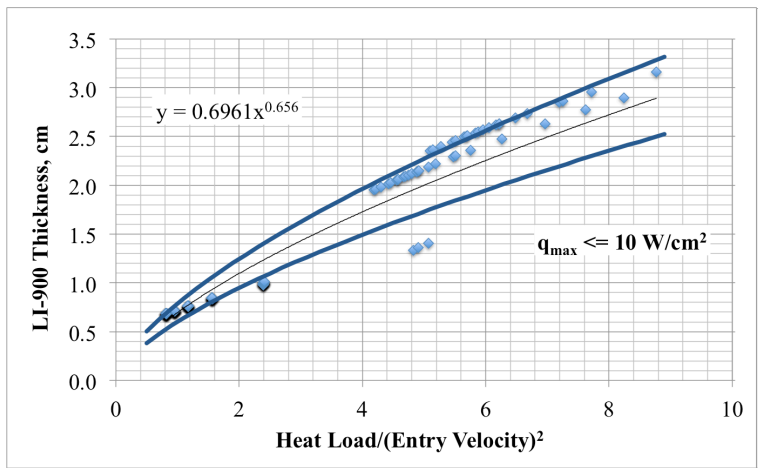

a) $\mathrm{qmax}<=10 \mathrm{~W} / \mathrm{cm}^{2}$

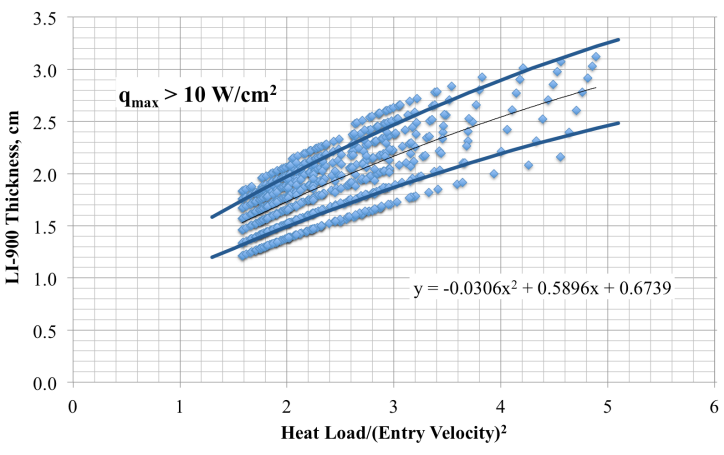

a) qmax $>10 \mathrm{~W} / \mathrm{cm}^{2}$

Figure 12. LI-900 MER

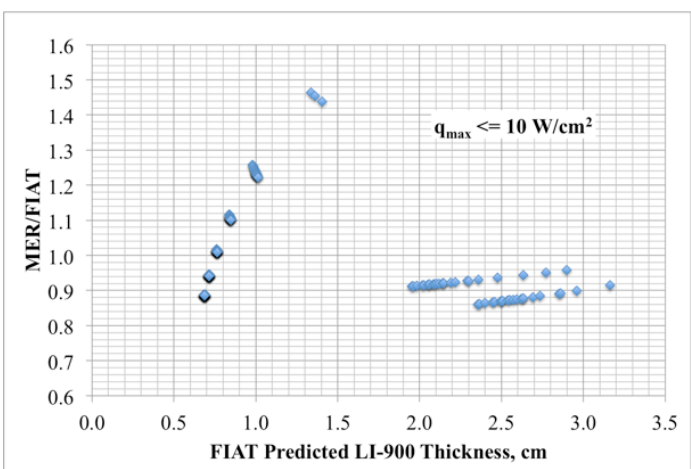

a) $\mathrm{qmax}<=10 \mathrm{~W} / \mathrm{cm}^{2}$

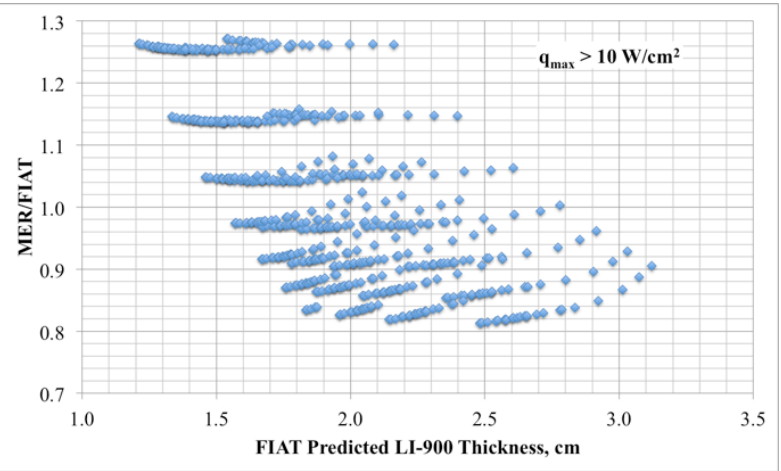

a) $\mathrm{qmax}>10 \mathrm{~W} / \mathrm{cm}^{2}$

Figure 13. LI-900 MER Goodness of Fit

\section{PICA Arcjet Testing Database}

For all the trajectories considered in this work, the highest predicted heating is over $3700 \mathrm{~W} / \mathrm{cm}^{2}$. PICA has never been tested under such high heating conditions (see Fig. 14), and it is unlikely to survive such a harsh environment. Figure 14 shows the heat flux for several successful PICA arc jet tests ${ }^{35,36,37}$. The PICA MER is limited to a cold-wall peak heating of $1200 \mathrm{~W} / \mathrm{cm}^{2}$, and M-SAPE has been configured so that a user is notified if a trajectory exceeds its MER limit. As a comparative note, it was estimated that a peak heat flux of about $1220 \mathrm{~W} / \mathrm{cm}^{2}$ was experienced on the PICA heat shield of the Stardust ${ }^{38}$ capsule. 


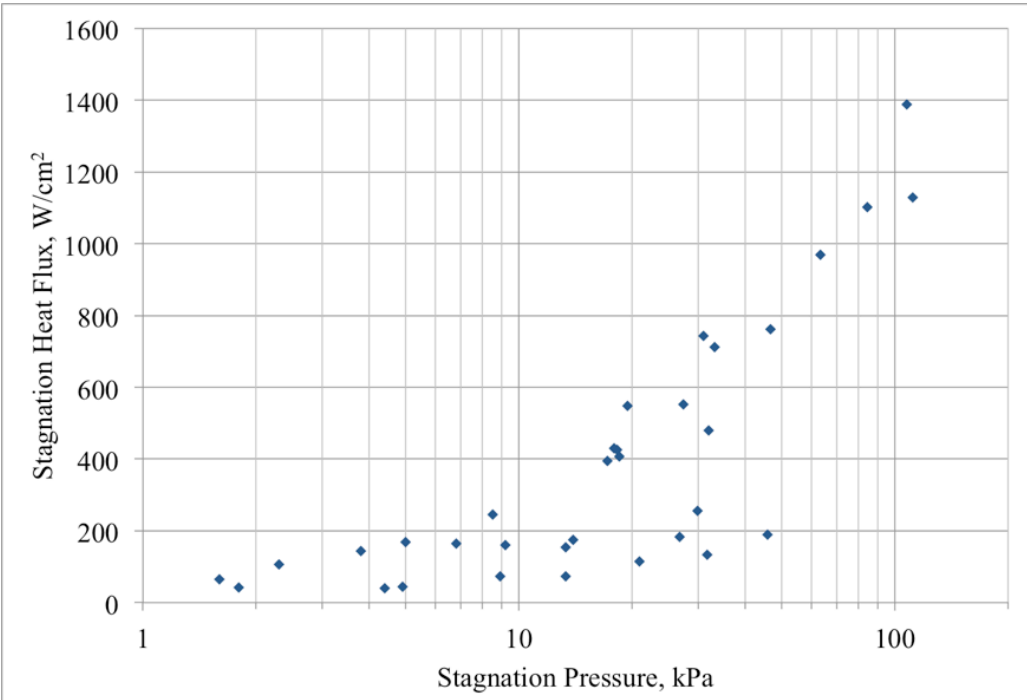

Figure 14. Successful Stagnation Tests of PICA in which no spallation was observed. Heat flux values are cold-wall.

\section{Conclusion}

Mass estimating relationships have been presented for the vehicle forebody ablators PICA and Carbon Phenolic atop ACC, and for the backshell materials SIRCA, Acusil II, SLA-561V, and LI-900. These MERs are accurate to FIAT prediction between $7 \%$ to $14 \%$ at one standard deviation. The most any MER can under predict FIAT is 18.7\% Applications include quick estimates of TPS mass during early stages of vehicle design. These MERs have been integrated into M-SAPE and used with FIAT as an initial estimate of required material thickness to speed up sizing estimates. When using these MERs, care needs to be taken so that sizing environments, such as peak heating, are within the capabilities of the material. Using these MERs has reduced design turnaround times for a possible Earth entry configuration from weeks to hours.

\section{Acknowledgments}

The authors gratefully acknowledge the support provided by the Thermal Protection Materials Branch (TSM) and the Aerothermodynamics Branch (TSA) of NASA Ames Research Center, through NASA Contract No. NNA10DE12C to the ERC Incorporated. Special thanks also go to Richard Winski for supplying the 840 trajectories covering the trajectory space considered for this work. 


\section{References}

${ }^{1}$ Samareh, J. A., Glaab, L., Winski, R. G., Maddock, R. W., Emmett, A. L., Munk, M. M., Agrawal, P., Sepka, S., Aliaga, J.,
Zarchi, K., Mangini, N., Perino, S., Bayandor, J., Liles, Charles, "Multi-Mission System Analysis for Planetary Entry (M-SAPE)
Version 1," NASA/TM-2014-218507, Aug. 2014.
${ }^{2}$ Wright, M.W., White, T., and Mangini, N., Data Parallel Line Relaxation (DPLR) Code User Manual Acadia Version
4.01 .1 , NASA/TM-2009-215388, October 2009.
${ }^{3}$ Gnoffo, P. A., "An Upwind-Biased, Point-Implicit Relaxation Algorithm for Viscous, Compressible Perfect-Gas Flows,"
NASA TP 2953, 1990
${ }^{4}$ Chen, Y.-K., and Milos, F. S., "Fully Implicit Ablation and Thermal Analysis Program (FIAT)," Journal of Spacecraft and
Rockets,Vol. 36, No. 3, pp 475-483, May-June 1999
${ }_{5}^{5}$ Moyer, C. B., and Rindal, R. A., "An Analysis of the Coupled Chemically Reacting Boundary Layer and Charring Ablator
- Part II. Finite Difference Solution for the In-Depth Response of Charring Materials Considering Surface Chemical and Energy
Balances", NASA CR-1061, 1968.
${ }_{6}$ Amar, A.J., Calvert, N.D., and Kirk, B.S., "Development and Verification of the Charring Ablating Thermal Protection
Implicit System Solver" AIAA paper 2011-144, presented at: 49th AIAA Aerospace Sciences Meeting including the New Horizons Forum and Aerospace Exposition, 4 - 7 January 2011, Orlando, Florida

${ }^{7}$ Curry, D. M., “An Analysis of a Charring Ablation Thermal Protection System”, NASA TN D-3150, November 1, 1965.

8 Sutton, K., Graves, R.A., “A General Stagnation-Point Convective Heating Equation For Arbitrary Gas Mixtures” NASA TR R-376, November 1971.

9 Tauber, M.E., Sutton, K., "Stagnation-Point Radiation Heating Relations for Earth and Mars Entries" AIAA Journal of Spacecraft, Vol. 28, No. 1.

${ }^{10}$ Hui, T., Johnson, C., Rasky, D., Hui, F., Hsu, M., Chen, Y-K., "Phenolic Impregnated Carbon Ablators (PICA) For Discovery Class Mission”, NASA Tech Briefs AIAA paper 1996-1911, presented at 31st AIAA Thermophysics Conference, New Orleans, LA, June, 1996.

11 Clements, H.R. and Ward, G.T., "Fabrication of Ablative Liners for Large Solid Booster Nozzles", J. SPACECRAFT VOL. 3, NO. 4, April 1966

${ }^{12}$ Tran, H.; Johnson, C.; Rasky, D.; and Hui, F. "Silicone Impregnated Reusable Ceramic Ablators for Mars Follow-on Missions", AIAA Paper 96-1819, June 1996.

${ }^{13}$ Edquist, Karl T.; Dyakonov, Artem A.; Wright, Michael J.; Tang, Chun Y., "Aerothermodynamic Design of the Mars Science Laboratory Backshell and Parachute Cone" 41st AIAA Thermophysics Conference; 22-25 Jun. 2009; San Antonio, Texas; United States, AIAA Paper 2009-4078.

${ }^{14}$ Squire, T., Milos, F., Agrawal, P., "Analytical Predictions of Thermal Stress in the Stardust PICA Heatshield Under Reentry Flight Conditions", National Space and Missile Materials Symposium, 28 Jun. - 1 Jul. 2009, Scottsdale, AZ, USA

${ }^{15}$ Milos, F.S., Chen, Y.K., "Two-Dimensional Ablation, Thermal Response, and Sizing Program for Pyrolyzing Ablators", AIAA paper 2008-1223, 46th AIAA Aerospace Sciences Meeting and Exhibit, 7 - 10 January 2008, Reno, Nevada.

${ }^{16}$ Edquist, K., Wright, M.J., and Allen, G., "Viking Afterbody Heating Computations and Comparisons to Flight Data"

AIAA paper 2006-386, 44th AIAA Aerospace Sciences Meeting and Exhibit, January 2006, Reno, Nevada

${ }^{17}$ Bulmer, B., "Study of Base Pressure in Laminar Hypersonic Flow: Re-entry Flight Measurements" AIAA Journal Vol., 13, No. 10, pp. 1340-1348.

${ }^{18}$ Milos, F.S., Gasch, M.J., and Prabhu, D.K., "Conformal Phenolic Impregnated Carbon Ablator (C-PICA) Arcjet Testing, Ablation and Thermal Response" AIAA paper 2015-1448, 53rd AIAA Aerospace Sciences Meeting January 2015, Kissimmee, Florida

${ }^{19}$ Kontinos, D., and Wright, M.J. "Introduction: Atmospheric Entry of the Stardust Sample Return Capsule" J. Spacecraft and Rockets Vol. 47, No. 6, November-December 2010

${ }^{20}$ Szalai, C., Slimko, E., and Hoffman, P., "Mars Science Laboratory Heatshield Development, Implementation, and Lessons Learned" J. Spacecraft and Rockets, Vol. 51, No. 4, July-August 2014

${ }^{21}$ Milos, F., Chen, Y.-K., Squire, T.H., and Brewer, R.A. "Analysis of Galileo Probe Heat Shield Ablation and Temperature Data” AIAA paper 1997-2480, 32nd Thermophysics Conference 1997 Atlanta, GA

${ }^{22}$ Bienstock, B.J., "Pioneer Venus and Galileo Entry Probe Heritage," International Planetary Probe Workshop, Lisbon, Portugal, Oct. 2003.

${ }^{23}$ Stokes, E.H. "A New Technique for Determining Fiber, Filler, Resin, and Volatile Content of Fully Cured Polymer Matrix - Carbon Fiber Composites” AIAA paper 98-3976, presented at 34th AIAA/ASME/SAE/ASEE Joint Propulsion Conference \& Exhibit July 13-15,1998 Cleveland, OH

${ }^{24}$ Clayton, W.A., "Thermal Conductivity Of Phenolic-Carbon Chars” Technical Report AFML-TR-69-313 December 1969

${ }^{25}$ Szalai, C. Chen, Y.-K., Loomis, M., Thoma, B., and Buck., S., "Mars Exploration Rover Transverse Impulse Rocket Cover Thermal Protection System Design Verification" J. Spacecraft and Rockets Vol. 42, No. 6, November-December 2005

${ }^{26}$ Milos, F., Chen, Y.-K., Congdon, W., and Thornton, J. "Mars Pathfinder Entry Temperature Data, Aerothermal Heating, and Heatshield Material Response," J. Spacecraft and Rockets Vol. 36, No. 3, May-June 1999

${ }^{27}$ Witkowski, A. Bruno, S., "Mars Exploration Rover Parachute Decelerator System Program Overview" AIAA paper 20032100, 7th AIAA Aerodynamic Decelerator Systems Technology Conference and Seminar AIAA 2003-2100 19-22 May 2003, Monterey, California. 
${ }^{28}$ Edquist, K., Dyakonov, A., Wright, M.J., and Tang, C., "Aerothermodynamic Design of the Mars Science Laboratory Backshell and Parachute Cone," AIAA paper 2009-4078, $41^{\text {st }}$ AIAA Thermophysics Conference, June 2009, San Antonio, TX

${ }^{29}$ Wright, M.J., Beck, R.A.S., Edquist, K., Driver, D., Sepka, S., Slimko, E., and Willcockson, W., "Sizing and Margins Assessment of Mars Science Laboratory Aeroshell Thermal Protection System", J. Spacecraft and Rockets Vol. 51, No. 4, JulyAugust 2014

${ }^{30}$ Laub, B., Chen, Y.-K., and Dec, J. "Development of a High-Fidelity Thermal/Ablation Response Model for SLA-561V" AIAA paper 2009-4232, 41st AIAA Thermophysics Conference 22 - 25 June 2009, San Antonio, Texas.

31 Edquist, K., Dyakonov, A., Wright, M.J., and Tang, C., Aerothermodynamic Design of the Mars Science Laboratory Heatshield, AIAA paper 2009-4075, $41^{\text {st }}$ AIAA Thermophysics Conference, June 2009, San Antonio, TX

${ }^{32}$ NASA Facts, "Orbiter Thermal Protection System" National Aeronautics and Space Administration, FS-2004-09-014-KSC (Rev. 2006).

33 Moser, T. and Schneider, W. "Strength Integrity of the Space Shuttle Orbiter Tiles" AIAA paper 81-2469 AIAA/SETP/SFTE/SAE/ITEA/IEEE 1st Flight Testing Conference November, 1981 Las Vegas, Nevada

${ }_{34}^{34}$ Cooper, R. A., and Holloway, P. F., "The Shuttle Tile Story," Astronautics and Aeronautics, January 1981.

35 Milos, F.S. and Chen, Y.-K., "Ablation Predictions for Carbonaceous Materials Using Two Databases for Species Thermodynamics," Journal of Spacecraft and Rockets, Vol. 50, No. 2, 2013, pp. 245-255.

${ }^{36}$ Milos, F.S., Chen, Y.-K, and Gökçen, T., "Nonequilibrium Ablation of Phenolic Impregnated Carbon Ablator," Journal of Spacecraft and Rockets, Vol. 49, No. 5, 2012, pp. 894-904.

37 Milos, F.S. and Chen, Y.-K., "Ablation and Thermal Response Property Model Validation for Phenolic Impregnated Carbon Ablator," Journal of Spacecraft and Rockets, Vol. 47, No. 5, 2010, pp. 786-805.

${ }^{38}$ Park, C., "Calculation of Stagnation-Point Heating Rates Associated with Stardust Vehicle" AIAA paper 2005-190, 43rd AIAA Aerospace Sciences Meeting and Exhibit, January 2005, Reno, Nevada 